\title{
HVMANITAS
}

\section{La argumentatio en EI Tratado sobre la Tisana de Galeno}

\author{
Autor(es): López Rodríguez, Concepción
}

Publicado por: Imprensa da Universidade de Coimbra

URL

persistente:

URl:http://hdl.handle.net/10316.2/35081

DOI:

DOI:http://dx.doi.org/10.14195/2183-1718_66_8

Accessed : $\quad$ 26-Apr-2023 07:51:17

A navegação consulta e descarregamento dos títulos inseridos nas Bibliotecas Digitais UC Digitalis, UC Pombalina e UC Impactum, pressupõem a aceitação plena e sem reservas dos Termos e Condições de Uso destas Bibliotecas Digitais, disponíveis em https://digitalis.uc.pt/pt-pt/termos.

Conforme exposto nos referidos Termos e Condições de Uso, o descarregamento de títulos de acesso restrito requer uma licença válida de autorização devendo o utilizador aceder ao(s) documento(s) a partir de um endereço de IP da instituição detentora da supramencionada licença.

Ao utilizador é apenas permitido o descarregamento para uso pessoal, pelo que o emprego do(s) título(s) descarregado(s) para outro fim, designadamente comercial, carece de autorização do respetivo autor ou editor da obra.

Na medida em que todas as obras da UC Digitalis se encontram protegidas pelo Código do Direito de Autor e Direitos Conexos e demais legislação aplicável, toda a cópia, parcial ou total, deste documento, nos casos em que é legalmente admitida, deverá conter ou fazer-se acompanhar por este aviso. 
humanitas

Vol. LXVI

2014

IMPRENSA DA UNIVERSIDADE DE COIMBRA

COIMBRA UNIVERSITY PRESS 


\title{
LA Argumentatio EN EL TRATAdo Sobre la tiSANA DE \\ GALENO
}

\author{
Argumentatio in Galen's Peri PTISÁnes
}

CONCEPCIÓN LÓPEZ RODRÍGUEZ

Universidad de Granada clopez@ugr.es

\section{Resumen}

Se analiza el papel de la "argumentación" en el tratado Perì ptisánēs, teniendo en cuenta los procedimientos lógico-retóricos que Galeno utiliza para construir su obra, un ejemplo perfecto de lógos dietético.

Palabras Clave: Galeno, retórica, argumentación lógica, medicina dietética.

\begin{abstract}
The role of Argumentatio in the Perì ptisánēs is studied in the present paper, considering basically Galen's logical and rhetorical procedures in order to conform an exact example of dietetic lógos.

Key words: Galen, Rhetoric, logic argumentation, dietetic.

Al leer el texto del Perì ptisánēs, fui constatando el hecho, señalado ya por la crítica para otros tratados galénicos, de la permanente obsesión de Galeno por el trazado de un méthodos. Esta preocupación no solo radica en la necesidad de proporcionar una demostración científica de la materia con vistas a ser comprendido y aplaudido por un círculo intelectual ilustrado ${ }^{1}$.

1 Mattern 2008: 14 y ss. aborda, entre otros, el interesantísimo tema de la audiencia en las obras de Galeno: "The question of Galen`s motives and audience is important to the successful interpretation of his works...He most often wrote, as he tells us, at the request or insistence of those whom he calls philoi (friends) or hetairoi (companions)... Much
\end{abstract}


El interés de la demostración ${ }^{2}$ galénica en esta obra, articulada en un claro y efectivo méthodos, radica en la epistémē tanto como en la dóxa; en otras palabras: quiere dejar ante todos claro (entendidos y profanos en la materia) la verdad y la verosimilitud de lo que propone (para el seguimiento de muchos), pues, aunque resulta evidente por las palabras citadas que Galeno aspira a ser comprendido por un público amplio, también es cierto que el interlocutor del médico es un "tú" que muy bien podría registrar a un segundo médico o a un discípulo o ser un personaje ficticio, un "tú" impersonal. Ese "tú" irrumpe en el texto, no en las palabras iniciales, a semejanza de una "epístola", sino al final del capítulo segundo ( $Y$, si buscas una demostración de que el agua refresca...), cuando Galeno acude a cuestiones más técnicas sobre el proceso de su argumentación (no es misión de este discurso -lógos-actual, propuesto sobre la tisana, llevarla a cabo, excepto que es fría y húmeda...). Dos saberes perfectamente conocidos por el médico de Pérgamo, medicina y retórica, se aúnan en sus obras, dotándolas de esa cohesión lógica, que siempre procura no dejar resquicio alguno a la posibilidad de un desliz argumentativo o al ataque del oponente. Un circuito cerrado, perfectamente acabado, irrebatible en su estructura, es este tratadito del Perì ptisánēs.

Por su temática, el tratado pertenece a las obras clasificadas como "dietéticas" o "farmacológicas": se ocupa de las normas de elaboración de la tisana de cebada, sus posibles variantes, su debida aplicación y los beneficios que produce. Mark Grant ${ }^{3}$ comenta que alguna obra "dietética" galénica, en concreto On the Powers of foods, fue compuesta cuando ya Galeno percibía que su saber y su figura habían obtenido el suficiente reconocimiento social. La misma consideración podríamos aplicar al Perì

of Galen`s work was produced in a agonistic, or competitive, context and was intended specifically to refute or even to humiliate a rival o predecessor, even if in some cases he knew them only through their texts".

2 La importancia de la demostración (apódeixis) en la obra galénica ha sido señalada y estudiada por numerosos críticos; entre ellos, puedo citar la figura de R. J. Hankinson 1991: 15-16, quien opina lo siguiente: "That Galen was concerned with demonstration, apodeixis, there can be no doubt: he wrote a treatise in fifteen books on the subjects, and he constantly stresses the need both to learn the proper method of demonstration, and to practice it...", p. 15, y añade: "Demonstration consists in the proof of necessary conclusions by way of necessarily true premises...", p.16.

3 "It is perhaps significant that On the Powers of foods was published when Galen`s medical and social position was not in question, for this work is very much a practical manual...”. Cf. Grant 2000:10. 
ptisánēs, del que no se conoce la fecha de composición. Esta cuestión no deja de tener interés porque llevaría consigo, en parte, la posibilidad de plantear quiénes eran los oyentes de este lógos, en caso, claro está, de que no se trate de una obra destinada a la escritura. Parece que la respuesta, por ahora, resulta inviable, si nos referimos al oyente como auditorio concreto y presencial, pues no hay ninguna alusión en el tratado que nos pueda proporcionar indicios al respecto, al margen de la segunda persona ya señalada, con ambiguo matiz. Sin embargo, si nos atenemos a la consideración del oyente como destinatario de carácter universal, está claro: son los médicos y los pacientes, o, en este último caso, un colectivo amplio de personas, no un reducido grupo ilustrado, que en un momento dado puedan ser pacientes; y ello precisamente por el carácter de la temática de la obra, elaboración de la tisana de cebada, accesible a un numeroso público.

Comienza Galeno esta obra con un Proemio ${ }^{4} \mathrm{en}$ el que plantea brevemente el estado de la cuestión. Desde sus primeras palabras se aprecia el tono del tratado y su estilo relativamente "polemista"

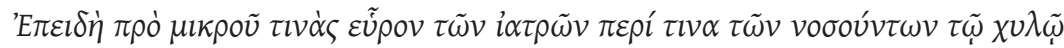

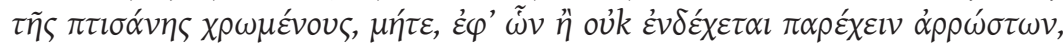

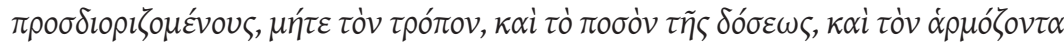

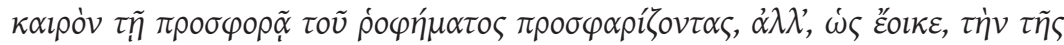

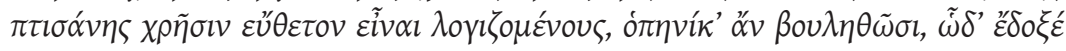

4 El Proemio en Galeno está estrechamente vinculado a lo que Jason König 2009:35-58 denomina genéricamente "Conventions of prefatory self-presentation" y, al margen de constituir en esencia un "rasgo galénico", también algunos de sus procedimientos aparecen estrechamente vinculados a las costumbres e ideales de la literatura del Imperio: "I am not arguing, then, that the Imperial obsession with compilatory writing was totally new, nor do I want to make claims for any kind of tightly bounded compilatory "genre". What I have suggested, however, is that some of the recurring features in the organizational techniques of Imperial knowledge -orderers- as well as being a symptom of the ancient tendency towards intellectual interdisciplinarity- are the result of similar struggles for disciplinary self-promotion that were replayed in many different contexts across the Roman Mediterranean".

El Perì ptisánēs no es un tratado de carácter compilatorio, pero sí apreciamos en las primeras palabras que pronuncia Galeno una alusión a costumbres ya establecidas que el propio autor propone de alguna manera cambiar, acudiendo al saber incuestionable de Hipócrates; en este sentido, pues, podemos decir también que Galeno "compila" acertadamente el saber del pasado remoto y del presente en una "actio" médico-farmacológica.

5 Según declara Mark Grant 2000:11, "The short treatise On Barley soup ... provides an interesting view of Galen`s polemical style...”. El texto griego utilizado pertenece a la edición de Kühn 1965: VI, 820-831. 


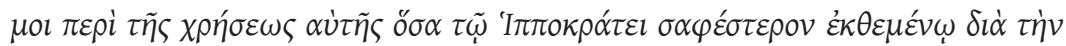
$\tau \tilde{\omega} v \pi \circ \lambda \lambda \tilde{\omega} v \pi \alpha \rho \alpha \kappa o \lambda o v ́ \theta \eta \sigma l v . .$.

Como hace poco tiempo descubrí que algunos de los médicos aplicaban la papilla de la tisana de cebada a alguno de los enfermos, no determinando en qué casos era aconsejable o no aplicárselo a los convalecientes, ni en qué manera ni cuánta era la dosis y el momento propicio para la administración de la papilla, sino que, según parece, consideraban que el empleo de la tisana era conveniente cuando ellos así lo estimaban oportuno, decidí explicar de forma más clara cuantas cosas fueron expuestas por Hipócrates sobre su uso, para seguimiento de muchos ${ }^{6} \ldots$

De las palabras citadas, se deduce que Galeno ofrece una alternativa nueva, en su opinión mucho más certera que la ofrecida por "algunos médicos" sobre la utilización de la tisana. Esta respuesta exige naturalmente la existencia de un contendiente, un interlocutor previo: son algunos médicos que ya han expresado su opinión. El agón científico es, por tanto, de carácter parcial, ya que uno de los oponentes no puede ofrecer su opinión, al menos en el texto consignado. No obstante, existe una parte de un posible debate. En realidad, parece que no queda nada sobre "las competiciones" o agones médicos y que sólo hemos de contentarnos con las inscripciones conservadas hasta hoy que registran los nombres de los vencedores en cada categoría, por lo que nos tenemos que conformar con la existencia de, al menos, la manifestación explícita de uno de los contendientes, el propio autor del tratado. Cabría también la posibilidad de que la alusión a "otros médicos" no sea otra cosa que un tópico galénico, en cuyo caso el carácter "polemista" del tratado no vaya más allá de ser un "fingimiento literario" 7 , orientado más bien a destacar la originalidad del propio Galeno sobre los demás. Pero, el médico de Pérgamo no se atreve o no quiere presentarse a sí mismo como "contrincante" único de esta contienda. Acude una vez más a la sagrada figura de Hipócrates, aureolada con la corona de la auctoritas $^{8}$,

6 Los textos citados en traducción del Perì ptisánēs son de la propia autora de este análisis del tratado. No existe en lengua castellana ninguna traducción del mismo. Mark Grant 2000, en lengua inglesa, ha traducido el tratado que se incluye en la obra titulada Galen on food and diet.

7 En este sentido, resulta útil consultar el estudio de Jason König 2009.

8 El ars retorica también contemplaba el recurso al criterio de autoridad como parte de las pruebas átechnoi. Tal recurso que está relacionado con el exemplum aparece 
indicando por tanto que no es responsable él de las palabras siguientes sino el maestro de todos los médicos griegos, cuya doctrina es aceptada sin fisuras. En tal caso pues, si existe alguna objeción, en última instancia a Hipócrates no a Galeno hay que pedir responsabilidades, aunque bien es verdad que en esta primera alusión a Hipócrates, Galeno se presenta como un hermeneuta de su predecesor y, "humildemente", en la apertura de su tratado, solo aspira a "revelar", "exponer de forma más clara" el significado más o menos oscuro de las palabras de aquel. Sin embargo, esta entrada relativamente modesta del médico de Pérgamo en la escena se va atenuando progresivamente $\mathrm{y}$, desde una posición privilegiada, se va produciendo como una inversión progresiva, de forma tal que es Galeno quien dice y es Hipócrates el que "testimonia", lo que constataremos en su momento. Por ahora, conviene reparar en las palabras finales de esta Introducción o Proemio, porque en ellas anuncia Galeno el método que se propone seguir, y que no es otro que un método retórico-dialéctico:

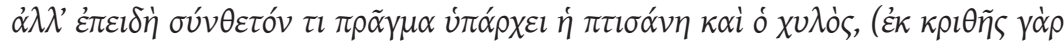

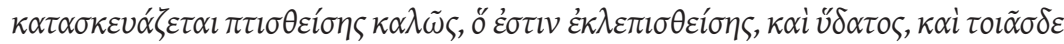

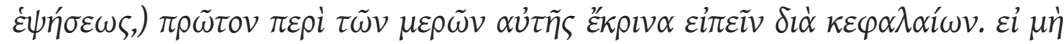

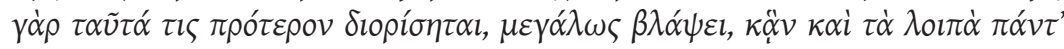
$\dot{\alpha} \kappa \rho \imath \beta о \lambda о \gamma \eta \dot{\sigma \varepsilon \varepsilon \tau \alpha l} \dot{\varepsilon} \varphi \varepsilon \xi \tilde{\eta} \varsigma$.

Pero, puesto que la tisana y su papilla es un compuesto, de cebada que ha sido mondada, de agua y de su cocción, primero me he propuesto hablar de sus partes. Pues, si no se determinan previamente, un gran daño podría producirse, aunque todas las restantes fueran examinadas con exactitud seguidamente.

Y este método está magistralmente descrito por Platón en el Fedro, cuando Sócrates pronuncia su segundo discurso, hecho que es referido por Luis Gil en su estudio introductorio a la magnífica traducción, donde además menciona a Hipócrates como usuario del mismo procedimiento:

recogido en Lausberg 1976: I, 359, donde se dice: "Si el orador logra establecer esa relación con la causa concreta, la fuerza persuasiva de la auctoritas es muy grande, precisamente en razón de la validez universal de la sabiduría que encierra y en virtud de la imparcialidad indubitable de que aparece revestida". Se acude aquí como referencia a la obra de Quintiliano (5.11.39.) 
$Y$ para realizar este análisis del alma se seguirá el método hipocrático empleado en el estudio del cuerpo, y que no es en esencia más que el método dialéctico... Se habrá de ver si algo es simple o compuesto. Si es algo compuesto, se enumerarán sus partes, y se procederá en cada una de ellas como en el caso de lo simple.

Termina aquí Galeno su Proemio, caracterizado como claro, conciso y efectivo, donde se aprecian con nitidez, desde el principio, las pautas compositivas de un lógos perfectamente estructurado, donde retórica y farmacología-médica aparecen vinculadas como las dos caras de una moneda o, por utilizar la terminología aristotélica, como los dos movimientos del coro.

Analizo a continuación los lógoi de este tratado: el dedicado al agua, el de la cebada y el de la cocción.

\section{PRIMER LÓGOS: el agua}

Conforme a lo anunciado en las últimas palabras del Proemio, prosigue Galeno su tratado, describiendo, en primer lugar, las características necesarias que ha de poseer el agua, un constituyente de esa "tisana", y que resume en una palabra: pura, hecho que se debe apreciar por el gusto, por el olfato y por la vista, como instrumentos de discernimiento, y zanja la cuestión con la siguiente frase: Que el agua más excelente ha de ser escogida para la preparación de la tisana, dejando pues en manos de "la percepción" (aísthēsis) el poder del conocimiento, criterio clave en la "adquisición del conocimiento", según Galeno. Ello, naturalmente lo acerca a la filosofía de tipo materialista, semejante a la epicúrea, por ejemplo y, de ahí, a un puro empirismo, de forma que podemos decir con Hankinson ${ }^{9}$ que Galeno es un empirista, incluso aunque no sea Empirista, porque parte de la evidencia de los sentidos. De ello da él mismo muestras cuando acusa a los sofistas de devaluar el conocimiento adquirido a través de la percepción.

Desglosa a continuación las propiedades del agua, destacando su fácil digestión y su rápido recorrido por el cuerpo; como punto de apoyo o prueba (pístis), de su argumentación cita de nuevo al gran Hipócrates: testigo (mártus) de mis palabras (lógou) ${ }^{10}$ es Hipócrates. Tal referencia,

9 Vid. R.J.Hankinson (2009: 214-215).

10 La traducción del término lógos presenta casi siempre varios problemas de interpretación. Si ello es así en términos generales, el texto galénico duplica y triplica las variantes posibles. Es conocida y comentada la polisemia galénica; pues bien, he aquí un 
inserta en el discurso, constituye, retóricamente hablando, una prueba átechnos ${ }^{11}$ del tema propuesto. Bien es verdad que posee esta característica también relativamente: el testigo (mártus) aportado por Galeno, en realidad no puede por sí mismo testimoniar porque pertenece a una época pasada, la que testimonia es su obra, que, por su propia naturaleza no admite diálogo alguno.

El procedimiento galénico para aportar pruebas de la veracidad de su argumentación se basa ahora en una especie de similitudo ("yo como Hipócrates", parece decir el autor del tratado), prueba basada en un procedimiento inductivo, aunque la demostración galénica opera prioritariamente con la deducción, o sea, con el silogismo. Por ello, incluso aquí, podemos reconstruir el razonamiento siguiente: Si la figura de Hipócrates no es cuestionada porque siempre acierta, dice la verdad, yo, Galeno, que mantengo las declaraciones de Hipócrates, también digo la verdad; luego mi teoría (diría el médico de Pérgamo) es cierta; nos encontraríamos, por tanto, en la inducción como premisa utilizada dentro de la deducción. El uso del silogismo como recurso argumentativo en Galeno ha sido señalado y estudiado por algunos críticos. J. Barnes ${ }^{12}$, entre otros, habla, en principio, de tres tipos de silogismo usados por el autor del Perì ptisánēs: el silogismo categórico aristotélico, el hipotético estoico o, el propiamente galénico, basado en las interrelaciones, aunque finalmente esta última especie no la reconoce como forma autónoma sino como una variedad híbrida creada a partir de las anteriores.

Galeno quiere ampliar el marco de su teoría y acude a la palabra "todos", justamente al final de este lógos dedicado a uno de los constituyentes de un complejo como es la tisana de cebada:

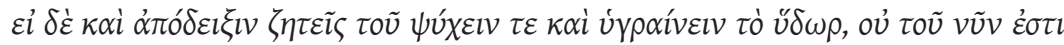

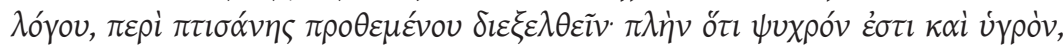

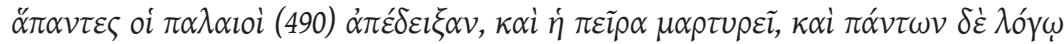

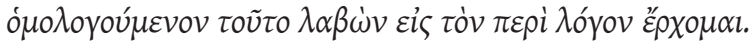

término complejo "por excelencia". De las numerosas apariciones en el Perì ptisánēs, unas veces se equipara a nuestro "discurso", en otras, sin embargo, está más cerca de "razón” y, en otras, más próximo a nuestra "argumentación".

11 Aristóteles, en su Retórica (I, 2.2), estableció, con gran claridad la diferenciación entre dos tipos de pruebas (písteis): pruebas éntechnoi ("técnicas", "artísticas") y pruebas átechnoi ("no técnicas", "no artísticas").

12 Cfr. J. Barnes (1997: 3). 
$Y$, si buscas una demostración de que el agua refresca y humedece, no es misión de este discurso (lógou) actual, propuesto sobre la tisana, llevarla a cabo, salvo (constatar) que es fría y húmeda, lo que todos los antiguos demostraron y la experiencia testimonia, y al estar todos de acuerdo en el razonamiento (lógōi), habiéndolo aceptado yo, me encamino al discurso (lógon) sobre la cebada.

Refuerza, pues Galeno "sus pruebas" -písteis- y acude a la expresión todos los antiguos demostraron, y, con ello pretende, no solo generalizar el referente sino también, en consecuencia, ampliar el campo de aplicación de su teoría: si en un principio Hipócrates decía y Galeno aclaraba, si después Hipócrates acudía como testigo (mártus) de las palabras de Galeno, ahora, justo al final de este lógos sobre el agua, si todos los antiguos demostraron, todos los de ahora deben comprenderlo, parece dejar implícito el texto.

Un concepto importantísimo en el méthodos galénico ha de ser analizado aquí: peĩra, la experiencia. En el texto arriba citado dice: la experiencia testimonia. Galeno, en efecto no renuncia a "la experiencia", que adquiere la validez de principio científico ${ }^{13}$, si consideramos el concepto desde el punto de vista de la teoría médica, y si lo consideramos desde un punto de vista retórico, cumple una función destacada en la argumentatio, y concretamente, en la argumentatio de este discurso, pues la usa como pístis, es decir, como prueba demostrativa; de ahí también su valor retórico. Se ha de precisar un poco el concepto de peĩra, que en este caso sugiere simplemente la "experiencia cotidiana" y que, como he dicho, Galeno utiliza de forma acumulada a las demás písteis. Sin embargo, no es esta la única ocasión en el Perì ptisánēs donde se constata la presencia de la peĩra; más adelante, el concepto se irá llenando de contenido "científico"

13 Resulta interesante en este punto las palabras de Armelle Debru en su artículo "Expérience, plausibilité et certitude chez Galen", in Galeno... (López Férez ed. (1991: 31 y ss): "Galien considère généralement son but atteint lorsqu'il est parvenu, selon ses propes termes, à substituer à des explications "plausibles" (pithanós) des démonstrations évidentes et scientifiques. L'opinion plausible (pithanòs lógos) a pour lui une existence essentiellement transitoire". Y añade más adelante (p. 34): "Une étape provisoire mais insuffisante vers le vrai; il ne manque qu'une preuve décisive pour en adquérir le statut. La preuve, qui est l'instrument de cette transformation, est fournie par des "évidences". Mais si l'expérience (empeiría, peĩra) qui s’applique à tous les domaines qui relèvent de la médicine propement dite, est souveraine, c'est bien parce qu`elle porte sur cette forme de connaissance provisoirement intermédiaire entre le vrai et le faux. Cela vaut pour la diététique et la pharmacologie". 
y presenciaremos la aparición de una "experiencia" mucho más amplia. Retomando el hilo conductor de lo ya expuesto sobre este concepto, aludiré al hecho de que el médico de Pérgamo nos presentaba un panorama en el que la práctica médica habitual era administrar la tisana cuando ellos lo consideraban oportuno (según declaraba el autor mismo en el Proemio ya citado). Si tenemos en cuenta tales palabras, debemos concluir que la tisana se administraba siguiendo un criterio voluntarista sin más, es decir, se acudía a una "experiencia sin cualificar". Galeno no está de acuerdo con esta simple empeireía, no sería científico. ¿Qué pretende entonces el autor de este tratado? Pretende ante todo establecer los principios de una experiencia que no sea mero fruto del capricho individual y del volátil kairós, una "experiencia cualificada"14, que halla su expresión también en un lógos cualificado (cfr. las últimas palabras del tratado: anankaíous diorismoús), es decir, medicina farmacológica y lógica-retórica aunadas, de forma tal que pueda surgir un producto en el que la expresión y el contenido resulten irreprochablemente trabados. La peĩra galénica aspira, pues, a convertirse en una demostración científica que trasciende el momento concreto, la aplicación concreta y al paciente concreto, tratando de crear un prototipo de validez universal, una "experiencia" de aplicación constante, una diorisménē peĩra. Considero, a continuación los aspectos argumentativos del segundo lógos.

\section{SEGUNDO LÓGOS: la cebada}

Siguiendo la ruta previamente trazada, se ocupa Galeno del segundo elemento que conforma "la tisana de cebada": la krithé (grano de cebada). Procede, en primer lugar, describiendo las partes del objeto (siguiendo, por tanto, la metodología ya comentada y las pautas argumentativas ya marcadas por el autor en su discurso sobre el agua): la parte más externa, que es la más seca y depurativa; la parte interior, más carnosa y depurativa y la parte intermedia. Una vez distinguidas las diferentes secciones de la materia -diaíresis- y expuestas brevemente sus propiedades (la cebada, como es universalmente reconocida, refrigera y seca, y contiene también algo de depurativo y flatulento), nos ofrece la caracterización de un buen producto. Para elegir las mejores cebadas, se ha de elegir un producto

14 Un análisis muy válido de la "experiencia cualificada" (diorisménē peĩra) lo encontramos en Philip J. van der Eijk (1996: 35-59), en su trabajo "The concept of "Qualified experience" in Galen on Pharmacology (ed. Armelle Debru). 
que no sea ni demasiado reciente, ni demasiado pasado -viejo- porque los nuevos están llenos de humedad y los viejos son débiles por el tiempo transcurrido; a ello añade como recurso argumentativo un sēmeĩon, un signo, y dice que los granos demasiado viejos presentan la característica del "arrugamiento" rutídōsis o la disminución de tamaño. Según sabemos, la utilización de sèmeĩa como recursos de la argumentatio y elemento de la prueba átechnon en calidad de señal de un factum, está prescrita por Aristóteles en su Retórica, siguiendo el autor por ello la normativa retórica más ortodoxa. A ello añade Galeno, una vez más, la verificación por la experiencia, de la forma siguiente: que la verificación por la experiencia ha de aducirse a estas, ratificando expresamente que "la experiencia" debe ser tenida en cuenta como un medio de verificación, o sea, que, retóricamente, pertenece a la categoría de las písteis átechnoi y, que, científicamente, ha de ser considerada, dentro de la actio médica como experimento demostrativo:

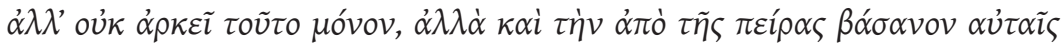

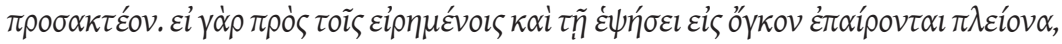

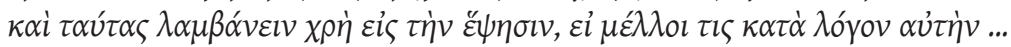

Pero no basta sólo con esto sino que la verificación por la experiencia ha de aplicárseles. Pues, si además de lo dicho, también por la cocción se infla, adquiriendo un volumen mayor, es necesario elegir estos (se refiere al tipo de granos de cebada) para la cocción, si se pretende hacer conforme a razón...

Naturalmente, no abandona sin más Galeno su lógos sobre la cebada, sino que, antes de darlo por concluido, recapitula (recapitulatio) lo hasta ahora expuesto:

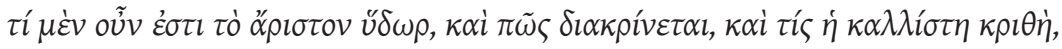

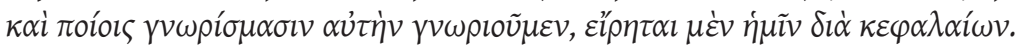

Entonces, cuál es la mejor agua y cómo se distingue y cuál es la óptima cebada y con qué signos de reconocimiento la reconoceremos, ha sido dicho por mí en sus aspectos principales.

\section{TERCER LÓGOS: la cocción}

Inicia Galeno su tercer y último lógos, siguiendo su trazado méthodos: no se preocupa tanto por dejar marcas señaladas de su argumentatio, marcas de 
nivel formal; en realidad, ya ha dejado sentadas las bases de sus recursos: el razonamiento, la experiencia cualificada, la tradición, el criterio de autoridad hipocrática, los signos del objeto considerado. Todo ello le ha llevado a presentar una apódeixis prácticamente irrefutable. Así nos habla Galeno:

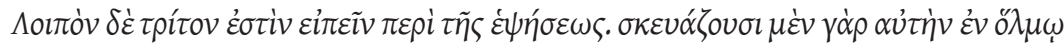

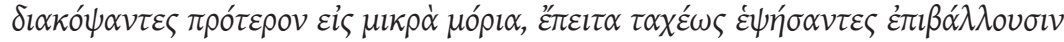

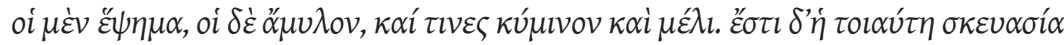

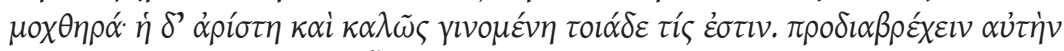

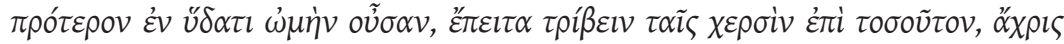

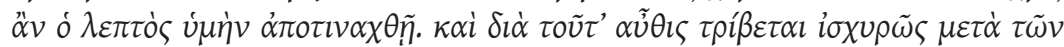

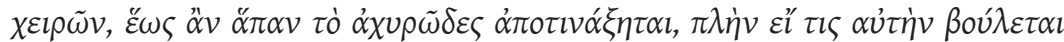

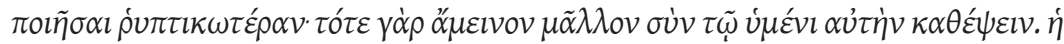

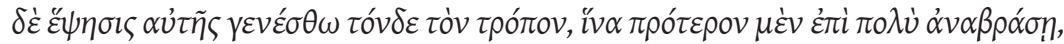

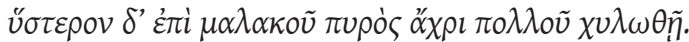

Lo tercero que resta es hablar sobre la cocción. Preparan esta en un mortero, machacándola en primer lugar en pequeñas porciones; luego, en seguida, tras cocerla, añaden unos mosto cocido, otros almidón y algunos comino y miel. Tal preparación es de mala calidad. La de más calidad y la que mejor resulta es la siguiente: remojar primero en agua la cebada cruda, luego, frotar con las manos hasta que la delgada membrana se desprenda. Y con este mismo método, de nuevo, se frota fuertemente con las manos hasta que toda la barcia se haya desprendido, a no ser que se quiera que esta tisana se haga más depurativa; entonces, es mucho mejor cocerla con la piel. Su cocción ha de hacerse del siguiente modo: que primero hierva bastante fuerte $y$, luego, a fuego suave, para que se reduzca bastante el jugo.

A pesar de todo, Hipócrates es traído de nuevo como mártus del argumento galénico. Ello constituye en realidad una pauta mnemotécnica que le sirve al autor del tratado del Perì ptisánēs para reforzar su credibilidad y como fórmula reiterativa conectora de su discurso global, amparándose, como dije antes, en la auctoritas de su predecesor:

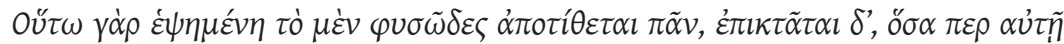
$\dot{\alpha} \gamma \alpha \theta \dot{\alpha} \dot{o}$ 'I $\pi \pi \circ \kappa \rho \alpha ́ \tau \eta \varsigma ~ \pi \rho о \sigma \mu \alpha \rho \tau u \rho \varepsilon \tilde{~}$

En efecto, cocida de esta forma, toda flatulencia ha sido anulada y se han obtenido cuantas cualidades Hipócrates confirma con su testimonio (prosmartireĩ). 
En su camino trazado (méthodos), Galeno va dejando todavía unas cuantas sèmeĩa de su argumentación, a modo, por ejemplo, de recapitulatio:

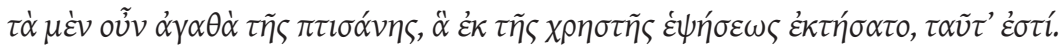

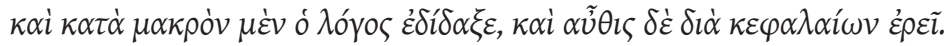

Por tanto, los beneficios de la tisana, que ha adquirido gracias a una buena cocción, son estos. El discurso (lógos) lo ha enseñado por extenso y, de nuevo, lo diré en sus puntos principales

También comenta Galeno, como buen médico, los casos en los que conviene la aplicación de la tisana; por ejemplo:

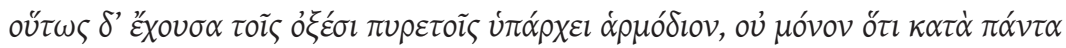

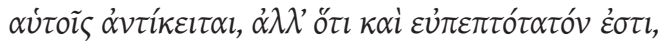

De ahí que sea apropiada para las fiebres agudas, no solo porque es lo opuesto a ellas sino también porque es extremadamente fácil de digerir...

Y finaliza su lógos con una recapitulación general de lo dicho:

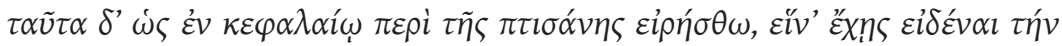

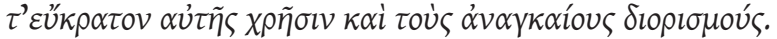

Sobre la tisana, que esto quede dicho por mí a modo de sumario, para que puedas saber el uso apropiado y las determinaciones precisas (anankaíous diorismoús).

Llama la atención, otra vez, el empleo galénico del término diorismós. La "especificación, determinación" que presupone el diorismós constituye en realidad un recurso utilizado por Galeno y que aparece en numerosas ocasiones vinculado a la experiencia ( $p$ eĩra), como muy bien ha manifestado Philip J. van der Eijk, y ya he comentado en su lugar. Ahora, sin embargo, justo al final del tratado, Galeno quiere destacar la calidad "científica" de sus recomendaciones, y emplea el término diorismoús nada menos que ligado al adjetivo anankaíous, donde, si ya de por sí el término lleva consigo una gran carga de "procedimiento meticuloso" (recuérdese a este respecto la traducción de peĩra diorisménē como "experiencia cualificada"), unido a lo "necesario" y "obligatorio", nociones que marca el concepto de la anánkē, 
presentes en el adjetivo, estamos ante una recapitulatio que con dos palabras resume la aspiración científica de su autor en este tratado y el interés constante en destacar que no se trata de una simple "recomendación farmacológica dietética", de interés casual.

En realidad, el Perì ptisánēs parece distribuido en dos secciones:

$1^{\circ}$ - Toda la parte en que Galeno se dedica a extender o cimentar la base técnico-lógica y retórica de su argumentatio; es la que hemos comentado un poco más detenidamente.

$2^{\circ}$-La segunda parte presupone y contiene, ya comprendidas por el lector-oyente, las pautas retórico-argumentativas, prescindiendo mucho más de términos técnicos, las recomendaciones médicas y los criterios fármaco-culinarios de la preparación de la tisana.

Esta diferenciación estructural nos hace pensar en la intención galénica a la hora de registrar esas pautas demostrativas técnicas; son demasiado evidentes como para no llamar la atención y podría haberlas camuflado a través de discretas sugerencias. Tal vez un deseo de aemulatio de los clásicos esté subyacente en ello; sin embargo, va más allá, de forma que, a veces, da la impresión de tratarse de un ejercicio retórico destinado a la enseñanza. En tal caso, el ilustre médico de Pérgamo podría ir configurando su discurso a la manera de un verdadero lógos, una pieza de oratoria o un escrito retórico; pero sus oyentes, sus destinatarios serían, por un lado, tal vez sus propios colegas, en un círculo más o menos limitado, y, por otro -desde una perspectiva distinta-, desde luego, los abrumados convalecientes, si bien la parte final, el epílogos, va dirigido a un "tú" en singular, un "tú" que, en resumidas cuentas, aclara poco la figura concreta del destinatario u oyente, porque puede tratarse de un "tú" de carácter "impersonal", no porque se trate de una "epístola" dirigida realmente a una sola persona. Lo que sí parece constatarse por lo dicho es que a Galeno le preocupa que su "discurso" sea percibido como verdadero por el auditorio en general y que sea ratificada su enseñanza por los especialistas como "verdad científica"; es decir le preocupa tanto la verosimilitud como la verdad o, por decirlo en términos griegos, la dóxa y la epistémē.

De esta forma, el Perì ptisánēs, al tiempo que se puede considerar como un lógos, también es, o pretende ser, un tratadito de dietética científico; de ahí las dos caras de esta única moneda, que es el Perì ptisánēs. 
Por último, y corroborando las palabras de Hankinson a cerca de la importancia de la demostración la obra galénica, diré que este es un ejemplo más del Galeno médico y del Galeno filósofo donde se aprecia el interés por la apódeixis.

\section{BIBLIOGRAFÍA}

Anderson, G. (1989), "The Pepaideumenos in Action: Sophists and Their Outlook in the Early Empire", Aufstieg und Niedergang der römischen Welt 2.33.1: 79-208.

Anderson, G. (1993), The second Sophistic: A Cultural Phenomenon in the Roman Empire. London: Routledge.

Barnes, J. (1997), "Logique et pharmacologie à propos de quelques remarques d`ordre linguistique dans le De simplicium medicamentorum temperamentis ac facultatibus de Galien", in Galen on Pharmacology. Leiden: Brill, 3-33.

Boudon, V. (1993), "Médecine et enseignement dans I'Art medical de Galien", Revue des études grecques 106: 120-41.

Boudon, V. (1994a), "Les oeuvres de Galien pour les débutans ("De sectis, "De pulsibus ad tirones", "Ad Glauconem de methodo medendi"): médecine et pédagogie au IIe siècle ap. J.-C., Aufstieg und Niedergang der römischen Welt 2.37.2: 1421-67.

Boudon, V. (1994b), "Loisir et creation littéraire chez Galien", Bulletin de l'Association Guillaume Budé 1994.2: 154-68.

Boudon-Millot, V. (2007), La science médicale antique: nouveaux regards. Paris: Beauchesne.

Boulogne, J. (1997), "L`apport de Galien à la méthode médicale", Revue des Études Grecques 110: 126-42.

Debru, A. ed. (1997), Galen on Pharmacology (Philosophy, History and Medicine). Leiden: Brill.

Debru, A. (1991), "Expérience, plausibilité et certitude chez Galien", in Galeno: Obra, pensamiento e influencia, J.A. López Férez ed. Madrid: UNED 31-41.

Frede, M. (1988), "The Empiricist Attitude to Reason and Theory", in R. J. Hankinson ed., Method, Medicine, Metaphysics. Alberta, (Apeiron XXI 2).

Gil Fernández, L. (1974), Platón: El Banquete, Fedón, Fedro. Madrid: Guadarrama.

Grant, M. (2000), Galen on food and diet. London and New York: Routledge.

Hankinson, R. J. (2009), "Galen on the limitations of Knowledge", in Galen and the world of knowledge, C. Grill, T. Whitmarsh and J. Wilkins. Cambridge: University Press, 206-242. 
Hankinson, R. J. (1991), "Galen on the foundations of science", in Galeno: Obra, Pensamiento e Influencia, J. A. Férez ed. Madrid: UNED, 15-29.

Jouanna, J. et Boudon, V. (1997), "Remarques sur la place d'Hippocrate dans la pharmacologie de Galien", in Galien on Pharmacology, ed. Armelle Debru. Leiden: Brill.

Koch, K., Helmreich, G., Karbfleisch, C. y Hartlich, O., (1923), De Ptisana, De Alimentorum Facultatibus, Corpus Medicorum Graecorum 5.4.2. Leipzig and Berlin: Teubner.

König, J. (2009), Conventions of prefatory self-presentation, in Galen and the world of Knowledge, C. Gill, T. Whitmarsh and J. Wilkins ed. Cambridge: University Press, 35-58.

Kühn, C. G. (1821-1889, reimp. 1965), Claudii Galeni, Omnia Opera. Leipzig: Georg Olms.

Lacy, P. (1972), “Galen`s Platonism”, American Journal of Philology 93: 27-39.

Lausberg, H. (1975), Manual de Retórica Literaria. Traducción de José Pérez Riesgo. Madrid: Gredos.

Mattern, S. P. (2008), GALEN \& the RHETORIC of HEALING. Baltimore: The Johns Hopkins University Press.

Nutton, V. (1991), "Style and Context in the Method of Healing”, in Galen 's Method of Healing: Proceedings of the 1982 Galen Symposium (Studies in Ancient Medicine 1), ed. Fridolf Kudlien and Richard J. Durling. Leiden: Brill, 1-25.

Pearcy, L. T. (1993), "Medicine and Rhetoric in the Period of the Second Sophistic", Aufstieg und Niedergang der römischen Welt 2.37.1: 445-56.

Singer, P. N. (1997), Galen. Selected Works. Oxford: University Press.

Smith, W. D. (1979), The Hippocratic Tradition. Ithaca, NY: Cornell University Press.

Spawforth, A. J. S. (1989), "Agonistic Festivals in Roman Greece”, in The Greek Renaissance in the Roman Empire, ed. Susan Walker and Averil Cameron. London: University of London, Institute of Classical studies, 193-97.

Von Staden, H. (1995), "Anatomy as Rhetoric: Galen on Dissection and Persuasion", Journal of the History of Medicine and Allied Sciences 50: 47-66.

Von Staden, H. (1997), "Galen and the "Second Sophistic", in Aristotle and after (Bulletin of the Institute of Classical Studies, Supplement 68), ed. Richard Sorabji. London: Institute of Classical Studies, School of Advanced Study, University of London, 33-54.

Tieleman, T. (1996), Galen and Chrysyppus On the Soul: Argument and Refutation in the De Placitis II-III. Leiden: Brill. 